\title{
Lactifluus dunensis, a new species from Rio Grande do Norte, Brazil
}

\section{Sá $\mathrm{MCA}^{\mathbf{1}}$, Baseia IG ${ }^{1}$ and Wartchow $\mathrm{F}^{\mathbf{2}}$}

\author{
${ }^{1}$ Universidade Federal do Rio Grande do Norte, Deptartamento de Botânica, Ecologia e Zoologia, Campus \\ Universitário, Lagoa Nova, CEP 59072-970, Natal, RN, BRAZIL. \\ ${ }^{2}$ Universidade Federal da Paraíba, Departamento de Sistemática e Ecologia/CCEN, CEP 58051-970, João Pessoa, PB, \\ BRAZIL
}

Sá MCA, Baseia IG, Wartchow F 2013 - Lactifluus dunensis, a new species from Rio Grande do Norte, Brazil. Mycosphere 4(2), 261-265, Doi 10.5943/mycosphere/4/2/9

Lactifluus dunensis is described as a new species from sand dune area in Brazil. It is characterized by the presence of orange-brown pileus with wrinkled then radially wrinkled at the margin, very long basidia, basidiospore size and abundant thin to slightly thick-walled pileipellis elements. Discussion, description, drawings and photographs of the new species are provided.

Key words - Agaricomycetes - Neotropic - Russulaceae - taxonomy

\section{Article Information}

Received 22 February 2013

Accepted 19 March 2013

Published online 3 April 2013

*Corresponding author: Mariana Sá - e-mail - marianasa85@gmail.com.br

\section{Introduction}

Recent molecular phylogenetic studies showed that Lactarius Pers. sensu lato and Russula Pers. are paraphyletic (Buyck et al. 2008). The genera accepted at the time were Russula, Multifurca Buyck \& V. Hosft. and an unresolved Lactarius that could be treated in two different genera (Buyck et al. 2008). Later Buyck et al. (2010) proposed to conserve Lactarius with a conserved type, $L a$. torminosus (Schaeff.: Fr.) Pers., with the argument to retain the name Lactarius for the larger clade to which La. torminosus belongs. Thus less than $20 \%$ of taxa have been transferred to Lactifluus (Pers.) Roussel (Verbeken et al. 2011, 2012, Stubbe et al. 2012).

From Northeast Brazil, only one species is known, La. rupestris Wartchow (Wartchow \& Cavalcanti 2010) from the semi-arid of Pernambuco state. Recently we received dry basidiomes and some field notes that correspond to an undescribed species. So we describe here the second milk-cap from the Northeast Brazil and the first from the Atlantic Forest of that region.

\section{Methods}

The basidiomes were collected at 'Parque Estadual das Dunas de Natal', municipality of Natal $\left(5^{\circ} 48^{\prime} \mathrm{S}-5^{\circ} 43^{\prime} \mathrm{S}, 35^{\circ} 09^{\prime}-\right.$ $35^{\circ} 12^{\prime} \mathrm{W}$ ), in the State of Rio Grande do Norte, Northeast Brazil. The area contains elements of Atlantic Forest mixed with some species in common with Caatinga and Coastal Tableland, where species of Leguminosae (all subfamilies), Myrtaceae, Poaceae, Asteraceae and Euphorbiaceae predominate (Freire 1990).

All micromorphological characters were observed from the dry samples and mounted in Congo red solution with $3 \% \mathrm{KOH}$, except for basidiospores that were measured in Melzer's reagent. Color codes and names follow Korneup \& Wansher (1978). 

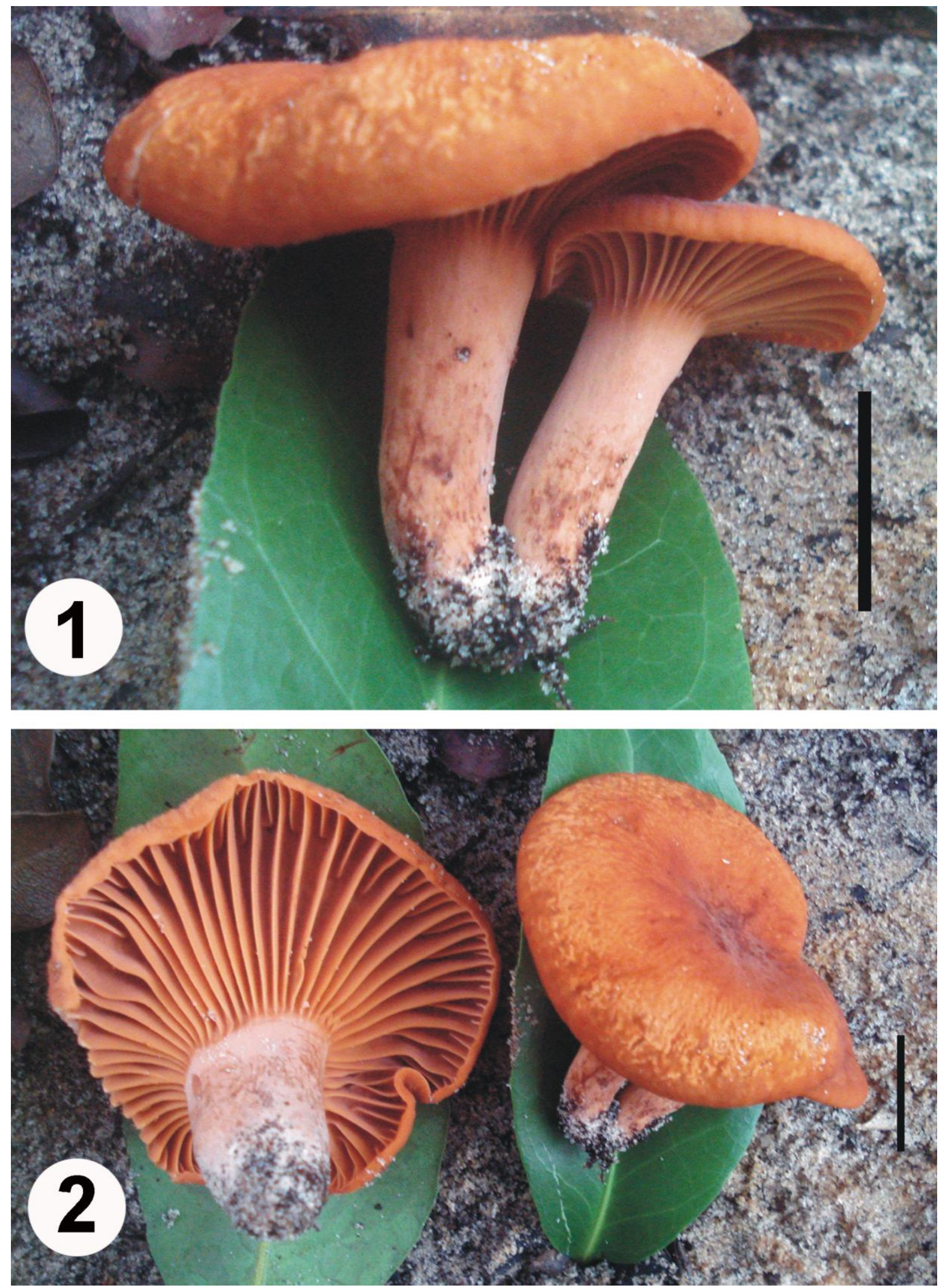

Figs 1-2 - Lactifluus dunensis (holotype). 1 Basidiomes in situ. Bars $=20 \mathrm{~mm}$. (Photo by J. Sousa).

Presentation of basidiospores data follows the methodology proposed by Tulloss et al. (1992), slightly modified here. Statistics are based on 30 basidiospores measured. Abbreviations include $\mathbf{L}(\mathbf{W})$ = basidiospore length (width) average from a single basidiome, $\mathbf{Q}=$ the length : width ratio range as determined from all measured basidiospores, and $\mathbf{Q m}=$ the $\mathbf{Q}$ value averaged from all basidiospores measured within a single basidiome. 


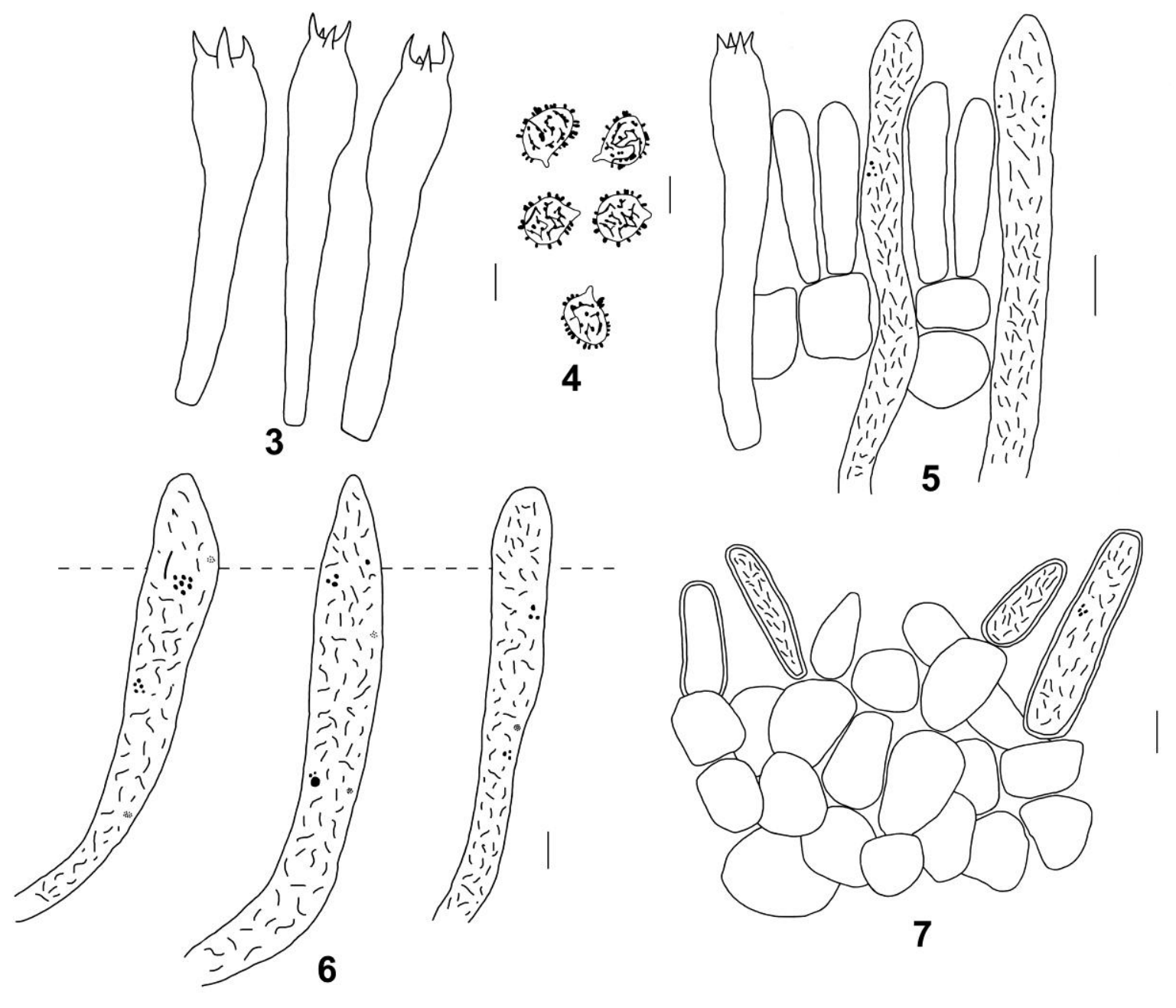

Figs 3-7 - Lactifluus dunensis (from holotype and isotype). 3 Basidia. 4 Basidiospores. 5 Hymenium showing basidium, basidioles and pseudocystidia. 6 Pseudocystidia with line showing the higher level of the other hymenial elements. 7 Pileipellis. Bars $=10 \mu \mathrm{m}$.

For Scanning electron microscopy (SEM) studies, sections were removed from dried basidiomata and mounted directly on aluminum stubs using carbon adhesive tabs. The fragments were coated with gold using a sputter coater and examined in a Shimadzu SSX-550.

\section{Results}

Lactifluus dunensis Sá \& Wartchow sp. nov.

MycoBank MB803355

(Figs 1-8)

Type - BRAZIL. RIO GRANDE DO NoRTE. Natal, Parque Estadual das Dunas de Natal, Trilha da Peroba, 21.vi.2012, J.C. Bezerra s.n. (UFRN-Fungos 1882 holotypus!, JPB 52375 isotypus!).
Etymology - regarding the habitat (sand dune area) where the new species was collected.

Pileus $60-110 \mathrm{~mm}$ in diam., slightly depressed; pellis dry, finely velvety, wrinkled and radially wrinkled at the margin, irregular surface, brownish orange (KW 6C8) at the context solid in dry. Lamellae short decurrent, light brown (KW 7D5), thick, distant; edge smooth, concolorous; lamellulae short short (one lamellula between lamellae), thick, smooth. Stipe $30-40 \mathrm{~mm} \times 10-20 \mathrm{~mm}$ at apex and $9-15 \mathrm{~mm}$ at base, central, slightly tapering toward to the base, brownish orange (KW 6C7) smooth, glabrous; context with soft consistence in dry specimens.

Basidiospores (6.1-)6.6-8.2(-8.7) $\times$ (5.6-)6.1-7.1(-7.7) $\mu \mathrm{m}, \mathbf{L}=7.5 \mu \mathrm{m}, \mathbf{W}=6.4$ 


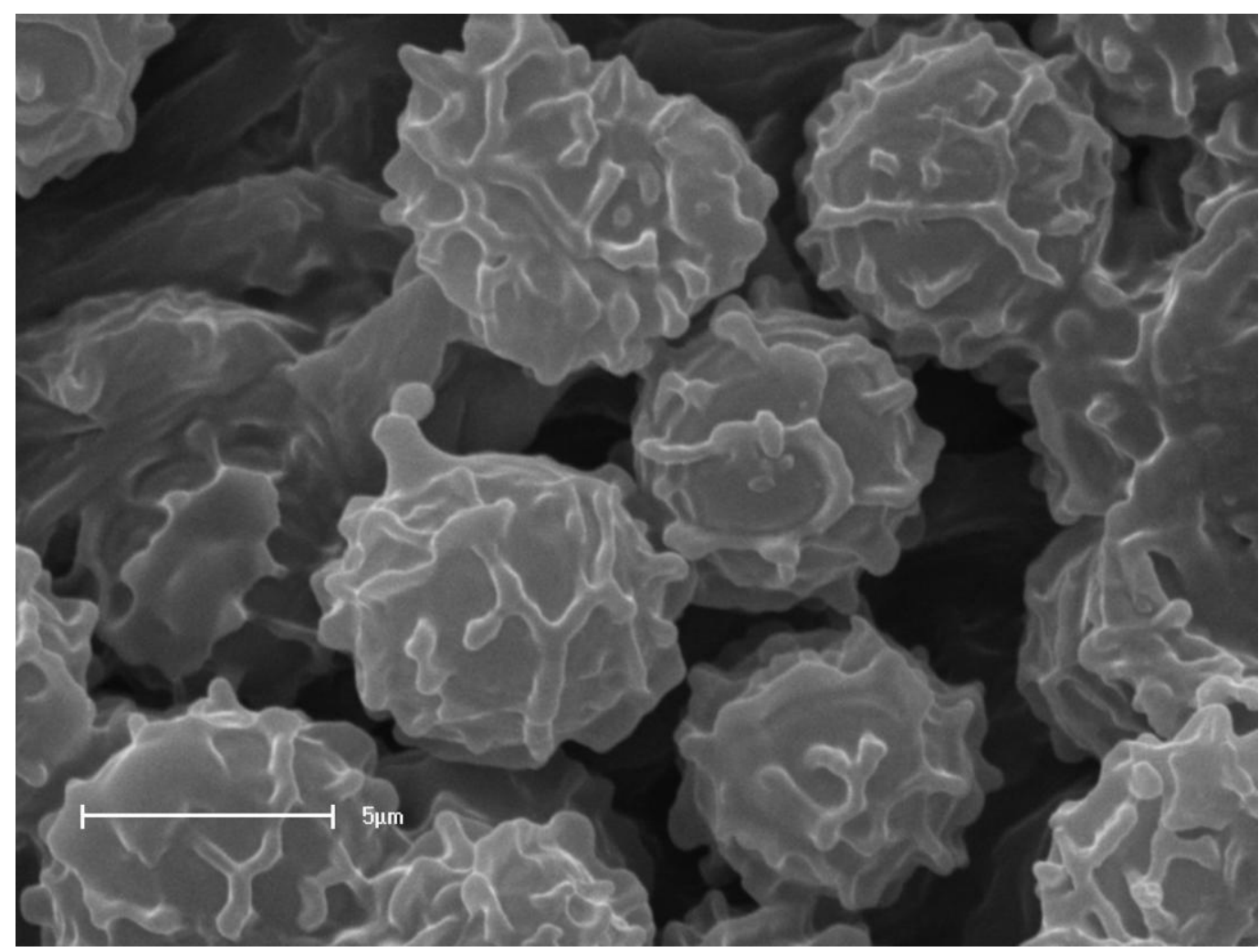

Fig. 8 - Scanning electron micrograph of the basidiospores of Lactifluus dunensis (from holotype). Bar $=5 \mu \mathrm{m}$.

$\mu \mathrm{m}, \mathbf{Q}=(1.00-) 1.10-1.40(-1.50), \mathbf{Q m}=1.20$ (excluding ornamentation), subglobose to ellipsoid, occasionally globose; ornamentation amyloid, composed of irregular, subspherical to subconical warts, up to $0.8 \mu \mathrm{m}$, forming a complete reticulum. Basidia 43-66 × 7.5-10 $\mu \mathrm{m}$, clavate, 4-spored, long and slender, sterigmata 4-6 $\mu \mathrm{m}$ high. Pleurocystidia absent. Pleuropseudocystidia abundant, slightly emergent, 7.7-9.7 $\mu \mathrm{m}$ diam., with brownish refractive contents, thin-wall, arising from deep in the hymenophoral trama. Lamella edge sterile; marginal cells $28-33 \times$ 5-6 $\mu \mathrm{m}$, cylindrical, thin-walled, hyaline. Hymenophoral trama composed of abundant sphaerocytes and abundant lactifers. Pileipellis a palisade up to $50-60 \mu \mathrm{m}$ thick; elements of suprapellis cylindrical $23-26 \times 5-6 \mu \mathrm{m}$, slender, with a rounded apex, slightly thickwalled; subpellis composed of isodiametric cells, $15-20(-31) \times 10-20(-26) \mu \mathrm{m}$, thinwalled. Clamp-connections absent.

Habitat - Gregarious on sandy soil in dune vegetation.

Known distribution - only known from the type locality.

\section{Discussion}

Lactifluus dunensis is characterized by the orange-brown pileus with wrinkled then radially wrinkled at the margin, very long basidia, basidiospore size and abundant thin to slightly thick-walled pileipellis elements.

According to Verbeken (1998), important characters of the sect. Rugati (Pacioni \& Lalli) Verbeken are the absence of true pleurocystidia, the presence of typical long and slender basidia and abundant pseupleurocystidia. She also subdivided the sect. Rugati into three subsections: subsect. Volemi, subsect. Luteoli and subsect. Rugati. Subsect. Rugati is characterized by the presence of elongate spores, with a distinct ornamentation consisting almost of a complete reticulum and the orange-brown pileus colour (Verbeken 1998). These features support the placement of our new species in $L f$. sect. Rugati subsect. Rugati.

Verbeken \& Walleyn (2010, as Lactarius) provided a key that separated the taxa of this subsection by the surface and colour of the pileus and length of the stipe. Among the African taxa, Lf. volemoides (Karhula) Verbeken and $L f$. 
pseudovolemus (R. Heim) Verbeken share with Lf. dunensis in the colour and the slightly wrinkled pileus (Verbeken \& Walleyn 2010). However, they are distinct from our new species as follows:

Lactifluus volemoides from Benin, Zambia and Zimbabwe differs from $L f$. dunensis in the white lamellae, larger basidiospores $8.5-10 \times 6-8.5 \mu \mathrm{m}, \mathbf{L}=9.5 \mu \mathrm{m}$, $\mathbf{W}=7 \mu \mathrm{m}, \mathbf{Q}=1.15-1.50, \mathbf{Q m}=1.40$, lower basidiospore ornamentation $(0.2 \mu \mathrm{m}$ high $)$ and the thick-walled terminal elements of the pileipellis, characterizing a lampropalisade (Verbeken \& Walleyn 2010).

In addition to pileus colour, the Malagasy Lf. pseudovolemus also shares with our new species basidiospores that are somewhat similar in size 7.0-9.0 × 5.4-6.6(-7) $\mu \mathrm{m} \mathbf{L}=8 \mu \mathrm{m}, \mathbf{W}=6 \mu \mathrm{m}, \mathbf{Q}=1.24-1.42, \mathbf{Q m}$ $=1.33$. However, the orange and narrow lamellae, the lower basidiospore ornamentation $(0.2 \mu \mathrm{m}$ high), the presence of 2 - or 3-septate suprapellis elements and the true pseudoparenchymatous subpellis are good features to segregate this species from $L$. dunensis (Verbeken \& Walleyn 2010).

The European type species of this section, Lf. rugatus (Kühner \& Romangn.) Verbeken also presents orange-brown pileus and proportionally short stipe. However, it differs from $L f$. dunensis in the cream coloured with ochraceous or orange shades and slightly bruising brown lamellae, slightly longer and narrower basidiospores (7.8-)8.1-9.5(-9.9) $\times$ (5.6-)5.9-6.6(-6.8) $\mu \mathrm{m}$, the pilleipellis with a lower layer of roundish cells, and the suprapellis with thin-walled hairs 3-4.5 $\mu \mathrm{m}$ wide (Lalli \& Pacioni 1992).

\section{Acknowledgements}

The authors wish thank the support from the Brazilian agencies: Conselho Nacional de Desenvolvimento Científico e Tecnológico ( $\mathrm{CNPq}$ ), Programa de Pesquisa em Biodiversidade (PPBio) and Programa de Capacitação em Taxonomia (PROTAX). We also acknowledge Julieth Sousa and Judcleidson Cavalcante Bezerra for the photographs and field notes. Also thanks to Dr. Maria Regina Barbosa and TAXON laboratory for the use of study and facilities.

\section{References}

Buyck B, Hofstetter V, Eberhardt U, Verbeken A, Kauff F. 2008 - Walking the thin line between Russula and Lactarius: the dilemma of Russula subsect. Ochricompactae. Fungal Diversity 28, 15-40.

Buyck B, Hofstetter V, Verbeken A, Walleyn R. 2010 - Proposal to conserve Lactarius nom. cons. (Basidiomycota) with a conserved type. Taxon 59, 295-296.

Freire MSB. 1990 - Levantamento florístico do Parque Estadual das Dunas do Natal. Acta Botanica Brasilica 4, 41-69.

Kornerup A, Wanscher JE. 1978 - Methuen Handbook of Colour. $3^{\text {th }}$ edition. London, Methuen.

Lalli G, Pacioni G. 1992 - Lactarius sect. Lactifluus and allied species. Mycotaxon 44, 155-195.

Stubbe D, Wang X-H, Verbeken A. 2012 New combination in Lactifluus. 2. L. sugen. Gerardii. Mycotaxon 119, 483485.

Tulloss RE, Ovrebo CL, Halling RE. 1992 Studies on Amanita (Amanitaceae) from Andean Colombia. Memoirs of the New York Botanical Garden 66, 1-46.

Verbeken A. 1998 - Studies in tropical African Lactarius species. 5. A synopsis of the subgenus Lactifluus (Burl.) Hesler \& A.H. Sm. emend. Mycotaxon 66, 363386.

Verbeken A, Walleyn R. 2010 - Monograph of Lactarius in Tropical Africa. Fungus Flora of Tropical Africa, Volume 2. National Botanic Garden of Belgium, Leuven.

Verbeken A, Nuytink J, Buyck B. 2011 - New combinations in Lactifluus. 1. L. subgenera Edules, Lactariopsis and Russulopsis. Mycotaxon 118, 447-453.

Verbeken A, Van de Putte K, De Crop E. 2012 - New combinations in Lactifluus. 3. L. subgenera Lactifluus and Piperati. Mycotaxon 120, 443-450.

Wartchow F, Cavalcanti MAQ. 2010 Lactarius rupestris a new species from the Brazilian semi-arid region. Mycotaxon 112, 55-63. 